BLANK, A.F.; FONTES, S.M.; OLIVEIRA, A.S.; MENDONÇA, M.C.; SILVA-MANN, R.; ARRIGONI-BLANK, M.F. Produção de mudas, altura e intervalo de corte em melissa. Horticultura Brasileira, Brasília, v.23, n.3, p.780-784, jul-set 2005.

\title{
Produção de mudas, altura e intervalo de corte em melissa
}

\author{
Arie F. Blank; Sany M. Fontes; Andréa dos S. Oliveira; Marcelo da C. Mendonça; Renata Silva-Mann; \\ Maria de Fátima Arrigoni-Blank
}

UFS - Depto. Eng. Agronômica, Av. Marechal Rondon s/n, B. Jardim Rosa Elze, 49100000 São Cristóvão-SE.

\begin{abstract}
RESUMO
O objetivo deste trabalho foi avaliar o efeito de recipientes e composições de substratos na produção de mudas e da altura e intervalo de cortes na produção de melissa (Melissa officinalis L.) em estufa agrícola. No ensaio de mudas empregou-se o delineamento inteiramente casualizado, em esquema fatorial $5 \times 4$, com três repetições, onde se avaliou cinco composições de vermicomposto (V) e esterco bovino (E) (nas proporções 1V:0E, 2V:1E, 1V:1E, 1V:2E e $0 \mathrm{~V}: 1 \mathrm{E})$ e quatro concentrações das composições no pó-de-coco (0; $20 ; 40$ e $60 \%$ ). No ensaio de altura e intervalo de corte utilizou-se o delineamento blocos casualizados, em esquema fatorial 4 × 2 , com três repetições, em parcelas subdivididas. Nas parcelas foram colocados os quatro intervalos de colheita $(8 ; 9 ; 10$ e 11 semanas após a primeira colheita) e nas subparcelas altura de corte $(5$ e $10 \mathrm{~cm})$. No ensaio de mudas a presença de vermicomposto nos substratos resultou em mudas vigorosas. Quando se usou 60\% de vermicomposto e $40 \%$ de pó de coco observou-se maior sistema radicular, seguido pelo substrato $26,7 \%$ de vermicomposto, $13,3 \%$ de esterco bovino e $60 \%$ de pó de coco, que também proporcionou mudas mais altas. No ensaio de altura e intervalo de corte, o corte a $5 \mathrm{~cm}$ de altura diminuiu a sobrevivência de plantas rebrotadas e não influenciou o peso seco de folha por planta. A colheita da rebrota pode ser feita 11 semanas após o primeiro corte.
\end{abstract}

Palavras-chave: Melissa officinalis, substrato, intervalo de colheita, altura de corte.

\begin{abstract}
Seedling production, cutting height and harvest interval in Melissa officinalis L.
\end{abstract}

The effect of recipients and substrate compositions was evaluated on seedling production, the height of cutting and harvest interval on the production of lemon balm (Melissa officinalis L.) cultivated in greenhouse. For the transplants trial a randomized experimental design in factorial scheme $5 \times 4$ with three replications was used. Five compositions of vermicompost $(\mathrm{V})$ and bovine manure (B) (1V:0B; 2V:1B; 1V:1B; 1V:2B; 0V:1B) and four concentrations of the compositions mixed with coconut dust $(0 ; 20 ; 40 ; 60 \%)$. For the harvest interval essay a completely randomized block experimental design was used, in a 4 × 2 factorial scheme with three replications using the split plot model. In the plots four harvest intervals (every $8 ; 9 ; 10$ and 11 weeks) and in the split-plots two cutting heights (5 and $10 \mathrm{~cm}$ ) were evaluated. In the seedling essay the presence of vermicompost on the substrate composition resulted in vigorous transplants. Better root system was observed in treatments using $60 \%$ of vermicompost and $40 \%$ of coconut dust followed by the substrate composed of $26.7 \%$ of vermicompost, $13.3 \%$ of bovine manure and $60 \%$ of coconut dust, which also proportioned highest plant height. In the regrowth essay the cutting at $5 \mathrm{~cm}$ of height resulted in a reduction of plant survival, and this fact did not affect the dry matter of leaves per plant. Harvesting of regrowth plants can be carried out eleven weeks after the first cutting.

Keywords: Melissa officinalis, substrate, harvest interval, cutting height.

(Recebido para publicação em 21 de julho de 2004 e aceito em 21 de maio de 2005)

\begin{abstract}
A melissa (Melissa officinalis L.), também chamada de erva-cidreiraverdadeira, pertencente à família Lamiaceae, é perene, arbustiva, podendo atingir de 30 a $100 \mathrm{~cm}$ de altura, caule quadrangular, herbáceo, ereto, piloso e aromático, ramificando-se a partir da base formando touceiras. As folhas são verde-escura na parte superior e verdeclara na parte inferior, com 5 a $8 \mathrm{~cm}$ de comprimento, são pecioladas, opostas, ovais, pilosas e com nervuras bem salientes. As flores, quando surgem são brancas ou amareladas, reunidas em fascículos de 2 a 6 unidades com florescimento de outubro a março na Europa (HERTWIG, 1986). No nordeste do Brasil esta espécie não floresce.
\end{abstract}

A planta possui atividade sedativa, tendo um papel importante no controle das emoções. É tranqüilizante e também indutora do sono. O citral, seu constituinte majoritário, é responsável pela ação relaxante (SADRAEI et al., 2003). O óleo essencial de M. officinalis produzida no nordeste brasileiro tem atividade antitumoral em trabalho realizado por Sousa et al. (2004).

$\mathrm{O}$ cultivo de plantas medicinais no Brasil ainda é muito incipiente e as espécies vegetais de interesse medicinal são coletadas, na maioria das vezes, sem a identificação correta da espécie e suas variedades e, muito menos, a época ideal de coleta (BACCHI, 1996), evidenciando a necessidade de estudos agronômicos de espécies com potencial medicinal. O primeiro passo nos estudos agronômicos é a produção de mudas de boa qualidade. Entre os diversos fatores que influenciam a qualidade da muda temse o substrato dentro os mais importantes. Este se constitui em elemento complexo desta atividade podendo ocasionar a nulidade ou irregularidade de germinação, podendo contribuir com a má formação das plantas e o aparecimento de sintomas de deficiência ou excesso de alguns nutrientes (SETUBAL; NETO, 2000).

Os substratos em geral têm como principal função dar sustentação às plantas tanto no ponto de vista físico como químico. Geralmente, os substratos são constituídos por três frações, a física, a biológica e a química. As frações físico-químicas são formadas por partículas minerais e orgânicas, contendo poros que podem ser ocupados pela água e/ou ar; a fração biológica é caracteri- 
zada pela presença da flora microbiana, fundamental no processo de nutrição das plantas (STURION, 1981).

A nutrição das plantas é diretamente influenciada pela composição do substrato utilizado, com níveis de nutrientes estando mais ou menos disponíveis, conforme maior ou menor quantidade de adubo adicionado. Matérias primas usadas na formulação de substratos podem dispor nutrientes, à medida que vão se decompondo ou se transformando. Outra influência é na capacidade de reter água (MINAMI, 2000). Os insumos a serem utilizados na composição dos substratos, devem manter qualidade, e serem disponíveis na região o que favorece o custo de obtenção. Este é o caso do pó-de-coco, facilmente encontrado no Estado de Sergipe, com preços acessíveis ao produtor, podendo ser utilizado na produção de mudas de várias espécies.

O Brasil, devido a sua grande extensão territorial, apresenta características edafoclimáticas peculiares a cada região, que podem interferir de modo positivo ou negativo no desenvolvimento das espécies nativas ou introduzidas, mesmo que as condições sejam semelhantes ao local de origem. Portanto, antes de iniciar o cultivo em escala comercial, faz-se necessário conhecer o comportamento da espécie com relação aos efeitos climáticos da região de plantio, os tratos culturais e os fatores bióticos que são responsáveis pelo desenvolvimento da planta. A falta de domínio tecnológico de todas as etapas de desenvolvimento levará, provavelmente, a baixa qualidade da biomassa e teores dos principais constituintes químicos do óleo essencial e nos rendimentos.

Com relação à altura de corte pouca informação foi encontrada na bibliografia consultada, sendo de grande importância pois dependendo da altura de corte, maior ou menor será o número de rebrotas e, conseqüentemente, maior biomassa. Cruz et al. (2001) com objetivo de determinar a altura e o número de cortes em alfavaca-cravo (Ocimum gratissimum L.), por meio de duas alturas de corte $(15$ e $30 \mathrm{~cm})$ e seis cortes consecutivos a intervalos de 45 dias, concluíram que a combinação do adensamento de plantio, com cortes a intervalos de 45 dias, iniciando aos 120 dias de idade, e a altura de corte de 30 $\mathrm{cm}$ do solo proporcionou maior produção de biomassa e óleo essencial. Em carqueja (Baccharis trimera D.C.), Mol et al. (2002) observaram que a colheita não deverá ser realizada por meio de cortes na altura do colo, sendo mais indicada a altura de $10 \mathrm{~cm}$.

Devido à grande demanda por plantas medicinais e aromáticas, muitos produtores têm se aventurado no seu cultivo, porém poucos estão obtendo êxito. Há falta de informações a respeito das técnicas de cultivo de cada região, uma vez que algumas das espécies hoje cultivadas no Brasil foram trazidas de outros países. Por essa razão torna-se necessário estudar o comportamento dessas espécies perante as práticas agronômicas, por meio da domesticação e do cultivo (CHAVES et al., 2002), principalmente na região Nordeste. A maior utilização desta espécie tem ocorrido em regiões do sul e sudeste do Brasil. O mercado interno de chás oferece $\mathrm{R} \$ 11,00$ por quilo de folha seca, sendo uma alternativa de renda do agricultor brasileiro. Desta forma, visando contribuir na definição de práticas destinadas à produção de melissa (Melissa officinalis L.), no trabalho avaliou-se o efeito de composições e concentrações de adubo orgânico na produção de mudas e de altura e intervalo de corte após a rebrota na produção de melissa em estufa agrícola.

\section{MATERIAL E MÉTODOS}

\section{Ensaio de mudas}

Foi conduzido na Fazenda Experimental "Campus Rural da UFS", situado no município de São Cristóvão-SE. Utilizou-se sementes comerciais de $M$. officinalis da empresa ISLA. A germinação das sementes foi feita em caixas tipo Gerbox em câmara de germinação com luz constante e $25^{\circ} \mathrm{C}$. Dez dias depois as plântulas foram submetidas aos respectivos tratamentos. O delineamento foi inteiramente casualizado, em esquema fatorial $5 \times 4$, com três repetições e quatro mudas por repetição. Avaliouse cinco composições de vermicomposto e esterco bovino (nas proporções $1: 0 ; 2: 1 ; 1: 1 ; 1: 2$ e $0: 1)$ e quatro concentrações das composições no pó-de-coco $(0 ; 20 ; 40$ e $60 \%)$. Utilizou-se tubetes de polietileno com capacidade para $110 \mathrm{~cm}^{3}$.

Aos 60 dias após o plantio das plântulas realizou-se a avaliação das seguintes variáveis: a) sobrevivência; foi realizada a contagem das plantas vivas da parcela, que foi expressa em porcentagem; b) altura de planta; foi medida a altura das mudas com o auxílio de fita métrica e calculou-se a média; c) número de folhas/planta; foi realizada a contagem das folhas das mudas de cada parcela; d) peso de folha, caule e raiz por planta; calculou-se a média do peso seco de folha, caule e raiz das mudas de cada parcela, em g/planta, usando-se balança semi-analítica; a secagem foi feita em estufa com fluxo de ar forçado a $105^{\circ} \mathrm{C}$ até peso constante; e) peso por folha; foi obtido dividindo-se o peso das folhas de cada muda pelo número de folhas por planta, expresso em gramas.

Os resultados das variáveis foram transformados sendo altura de planta, número de folhas/planta $\left((\mathrm{x}+1)^{0,5}\right)$, peso de raiz por planta $\left((\mathrm{x}+0,1)^{0,5}\right)$ e peso de folha e caule por planta e peso por folha $\left((\mathrm{x}+0,01)^{0,5}\right)$, submetidos à análise de variância e, observada a significância, aplicou-se o teste de Tukey $(\mathrm{P} \leq 0,05)$ e a regressão polinomial.

Ensaio de altura e intervalo de corte

Foi conduzido em estufa agrícola na estação experimental Campus Rural da UFS, localizado em São Cristóvão (SE), utilizando-se cobertura plástica preta para controle de plantas invasoras, em canteiros dimensionados em 1,20 m de largura e 9,60 m de comprimento. Utilizou-se sementes comerciais de melissa (M. officinalis) da empresa ISLA. A semeadura foi feita em bandejas de PVC, contendo esterco bovino, vermicomposto e pó-de-coco, na proporção 1:1:3. Após 30 dias, as mudas foram transferidas aos tubetes de 110 $\mathrm{cm}^{3}$, usando-se a mesma mistura. Após 40 dias realizou-se o transplante nos canteiros definitivos no espaçamento $0,25 \mathrm{~m}$ entre linhas e $0,30 \mathrm{~m}$ entre plantas em quatro linhas por canteiro. A adubação foi realizada com $4,5 \mathrm{~L} / \mathrm{m}^{2} \mathrm{de}$ biofertilizante comercial Vitasoloâ e 4,5 $\mathrm{L} / \mathrm{m}^{2}$ de esterco bovino, uniformemente misturados ao solo. O sistema de irri- 
Tabela 1. Valores médios de sobrevivência de mudas e peso por folha de melissa (M. officinalis), em função de misturas de adubos orgânicos (V= vermicomposto e $\mathrm{E}=$ esterco bovino) e concentrações dos adubos orgânicos no pó de coco. São Cristóvão (SE), UFS, 2002.

\begin{tabular}{lcc}
\hline Mistura de adubos orgânicos & Sobrevivência (\%) & Peso/folha (g) \\
\hline 1V:0E & $77,08 \mathrm{a}$ & $0,020 \mathrm{a}$ \\
2V:1E & $68,75 \mathrm{a}$ & $0,009 \mathrm{bc}$ \\
1V:1E & $72,92 \mathrm{a}$ & $0,012 \mathrm{~b}$ \\
1V:2E & $64,58 \mathrm{a}$ & $0,006 \mathrm{~cd}$ \\
OV:1E & $50,00 \mathrm{a}$ & $0,004 \mathrm{~d}$ \\
CV (\%) & 39,627 & 10,478 \\
\hline Concentração de adubo orgânico (\%) & \\
\hline 0 & 26,67 & 0,004 \\
20 & 88,33 & 0,010 \\
40 & 88,33 & 0,014 \\
60 & 68,33 & 0,013 \\
\hline \multirow{2}{*}{ Equação $(\mathrm{Y}=)$} & $29,5+3,475 \mathrm{x}-0,048 \mathrm{x}^{2}$ & $0,004+0,004 \mathrm{x}-0,000004 \mathrm{x}^{2}$ \\
\hline
\end{tabular}

* Médias seguidas de mesma letra nas colunas não diferem entre si a 5\% de probabilidade pelo teste de Tukey.

gação foi gotejamento e 30 dias antes do transplante realizou-se a calagem com calcário dolomítico visando $70 \%$ da saturação de bases.

O delineamento experimental constou de blocos casualizados em esquema fatorial $4 \times 2$, com três repetições, em parcelas subdivididas. Nas parcelas foram colocados os quatro intervalos de colheita $(8,9,10$ e 11 semanas após a primeira colheita) e nas subparcelas altura de corte $(5$ e $10 \mathrm{~cm})$. Cada subparcela foi composta por quatro linhas de quatro plantas e as quatro plantas centrais constituíram a parcela útil. O primeiro corte foi realizado em 29/ 05/2003, três meses após o transplante, cortando todas as plantas de acordo com o tratamento de altura de corte.

No segundo corte (rebrota), avaliouse as seguintes variáveis: a) sobrevivência; foi realizada a contagem das plantas vivas da parcela útil, que foi expresso em porcentagem; b) altura de planta; foi medida a altura das plantas com o auxílio de fita métrica, e calculou-se a média; c) peso seco de folha e caule; foi obtido por meio da média do peso seco das folhas e caules das plantas de cada parcela útil, expresso em g/planta, usando-se balança semi-analítica; a secagem foi feita em estufa com fluxo de ar forçado a $105^{\circ} \mathrm{C}$ até peso constante.

Não foi possível obter o terceiro corte por não haver sobrevivência após o segundo corte. Os resultados foram sub- metidos à análise de variância e, observada a significância, aplicou-se o teste de Tukey $(\mathrm{P} \leq 0,05)$ e a regressão polinomial.

\section{RESULTADOS E DISCUSSÃO}

\section{Ensaio de mudas}

As misturas de vermicomposto e esterco bovino não influenciaram significativamente a porcentagem de sobrevivência (Tabela 1). Quanto à concentração do adubo orgânico, observou-se que a regressão quadrática explicou a sobrevivência, sendo as concentrações de $20 \%$ e $40 \%$, as que resultaram na maior sobrevivência (Tabela 1). O maior peso por folha foi obtido quando usouse somente vermicomposto (Tabela 1). Quanto à concentração do adubo orgânico no pó-de-coco observou-se que a regressão quadrática explicou melhor a variável peso/folha, sendo que $40 \%$ proporcionou folhas com maior peso (Tabela 1). A interação mistura de adubos orgânicos e concentração das misturas foi significativa nas variáveis altura de planta, número de folhas/planta e peso de folha, caule e raiz secos por planta (Tabela 2).

Utilizando somente vermicomposto ou esterco bovino observou-se que a regressão linear da concentração do adubo orgânico explicou melhor a altura de planta (Tabela 2). Já nas misturas dos dois adubos orgânicos notou-se que a regressão quadrática da concentração explicou melhor a altura de planta, sendo que o uso de $40 \%$ da mistura no póde-coco proporcionou plantas mais altas. Em todas as misturas de adubo orgânico houve resposta quadrática de concentração do adubo na variável número de folhas/planta (Tabela 2). A composição do substrato é essencial ao desenvolvimento dessa variável. Em trabalho de Momenté et al. (2002), observouse que o substrato composto por Plantagro ${ }^{\circledR}$ + vermiculita proporcionou maior número de folhas/muda quando comparado com os substratos Plantagro ${ }^{\circledR}$ + vermiculita + solo e Plantagro ${ }^{\circledR}$ somente.

Quanto à variável peso seco de folha /planta a concentração do adubo orgânico dentro da mistura $2 \mathrm{~V}$ : $1 \mathrm{E}$ foi melhor explicada pela regressão linear e dentro das misturas $1 \mathrm{~V}: 0 \mathrm{E}, 1 \mathrm{~V}: 1 \mathrm{E}$ e $1 \mathrm{~V}: 2 \mathrm{E}$ os dados foram melhor explicados pela regressão quadrática (Tabela 2). A regressão linear dentro as misturas de adubos 1V:0E e 2V:1E foi a que melhor explicou os dados de concentração do adubo no peso seco de caule/planta; a regressão quadrática explicou melhor os dados de concentração do adubo dentro da mistura 1V:1E (Tabela 2). Quanto à concentração do adubo orgânico observou-se resposta linear dentro da mistura $1 \mathrm{~V}: 0 \mathrm{E}$ e quadrática dentro das misturas $2 \mathrm{~V}$ :1E e $1 \mathrm{~V}$ :2E na variável peso seco de raiz/planta (Tabela 2 ).

Confirmando a importância da composição do substrato, Bezerra et al. (2002) obtiveram maior peso fresco de raiz e parte aérea de melão-de-são-caetano (Momordica charantia) quando usaram substrato comercial Plugmix ${ }^{\hat{a}}$; os substratos vermiculita, solo e areia resultaram em menor peso. Blank et al. (2003) também observaram que os substratos vermicomposto e vermicomposto + pó de coco (1:1) proporcionaram mudas com maior sistema radicular e parte aérea. Notou-se que a presença de vermicomposto na composição dos substratos resultou em mudas mais vigorosas. O maior sistema radicular foi proporcionado quando usou-se $60 \%$ de vermicomposto e $40 \%$ de pó de coco, seguido pelo substrato composto por $26,7 \%$ de vermicomposto, $13,3 \%$ de esterco bovino e $60 \%$ de pó-de-coco, que também proporcionou mudas mais altas. 
Tabela 2. Valores médios de altura de planta (cm), número de folhas/planta, peso seco de folha/planta, de melissa (M. officinalis), em função da interação misturas de adubos orgânicos ( $V=$ vermicomposto e $E=$ esterco bovino) e concentrações dos adubos orgânicos no pó de coco. São Cristóvão (SE), UFS, 2002.

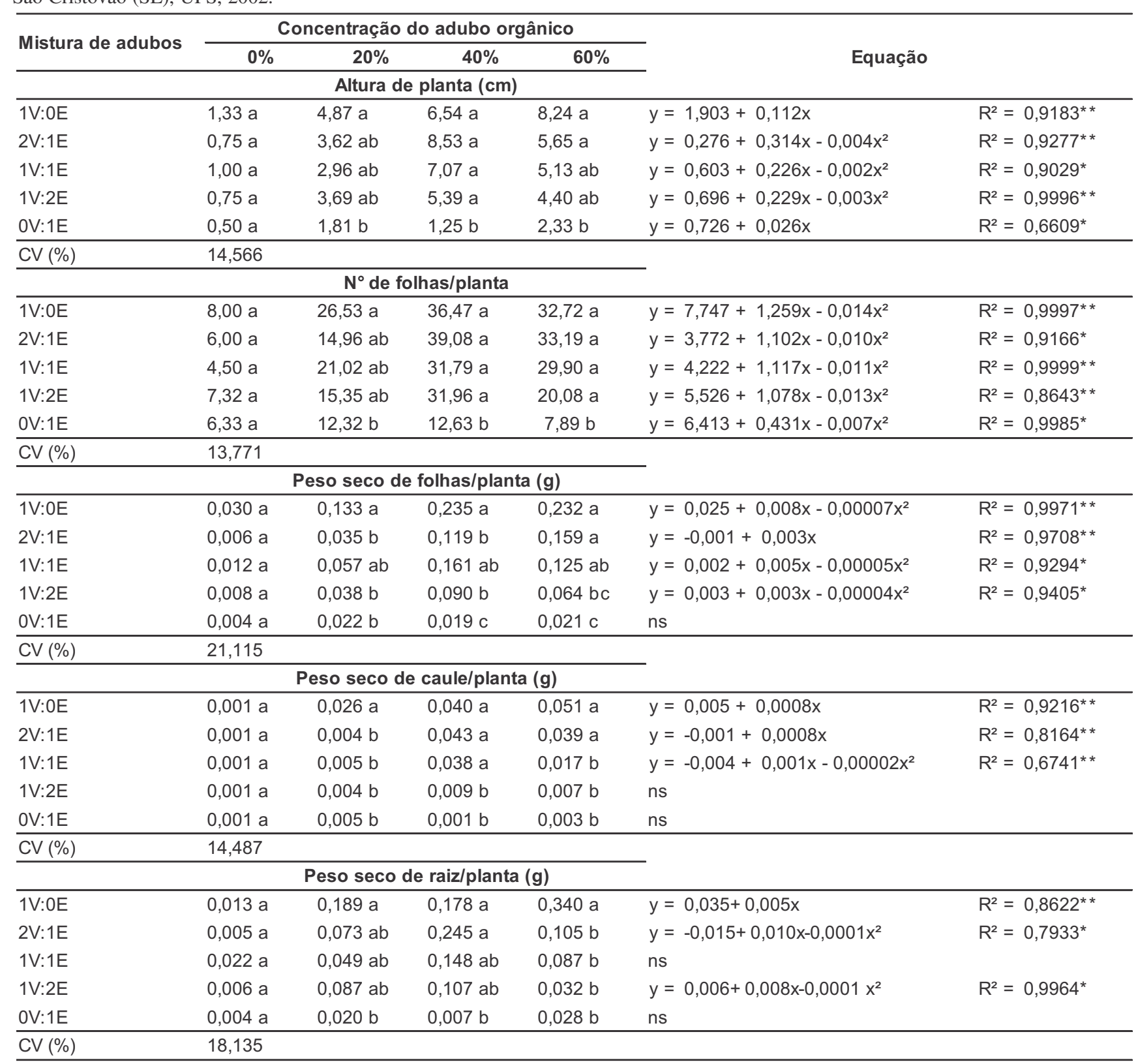

* Médias seguidas de mesma letra nas colunas não diferem entre si a 5\% de probabilidade pelo teste de Tukey.

\section{Ensaio de altura e intervalo de} corte

No primeiro corte, quando realizouse as alturas de corte de acordo com os tratamentos, observou-se altura média de $50,2 \mathrm{~cm}$ e $13,989 \mathrm{~g}$ de peso seco de folhas/planta e $8,406 \mathrm{~g}$ de caule seco/ planta. Geralmente, nos cultivos comerciais, após o primeiro corte o produtor estabelece novo plantio com a utilização de novas mudas. Visando o aproveitamento da rebrota (após a primeira colheita), usando cobertura plástica pre- ta sem a utilização de doses complementares de adubo, avaliou-se a produção antes da realização de mais colheitas. Foi possível realizar somente a segunda colheita, já que a sobrevivência não possibilitou o terceiro corte. Já em hortelã-rasteira (Mentha villosa), espécie também da família Lamiaceae, Innecco et al. (2003) conseguiram realizar quatro cortes com intervalo de 75 dias.

Por ocasião do segundo corte notouse que a altura de corte a $5 \mathrm{~cm}$ causou diminuição significativa da sobrevivên- cia das plantas (Tabela 3). Mol et al. (2002) observaram que o corte rente ao solo em carqueja (Baccharis trimera D.C.) também resultou na diminuição da sobrevivência. $O$ corte a $5 \mathrm{~cm}$ também proporcionou plantas mais baixas do que o corte a $10 \mathrm{~cm}$ (Tabela 8). Isto mostra que a melissa não mantém suas características de rebrota fácil, quando é cultivada no nordeste brasileiro, como acontece na Europa (HERTWIG, 1986). A altura de corte não influenciou significativamente o peso seco de folhas, mas 
Tabela 3. Valores médios de sobrevivência, altura de planta e massa de folha e caule secos por planta, em função da altura e intervalo de corte na segunda colheita de melissa $(M$. officinalis). São Cristóvão (SE), UFS, 2003.

\begin{tabular}{|c|c|c|c|c|}
\hline \multirow{2}{*}{$\begin{array}{l}\text { Altura de corte } \\
(\mathrm{cm})\end{array}$} & \multirow{2}{*}{$\begin{array}{c}\text { Sobrevivência } \\
(\%)\end{array}$} & \multirow{2}{*}{$\begin{array}{l}\text { Altura de planta } \\
(\mathrm{cm})\end{array}$} & \multicolumn{2}{|c|}{ Peso (g) } \\
\hline & & & $\begin{array}{c}\text { Folha } \\
\text { seca/planta }\end{array}$ & $\begin{array}{c}\text { Caule } \\
\text { seco/planta }\end{array}$ \\
\hline 5 & $75,0 \mathrm{~b}$ & $29,86 \mathrm{~b}$ & $8,514 \mathrm{a}$ & $5,480 \mathrm{~b}$ \\
\hline 10 & 100,0 a & 37,47 a & 9,262 a & 7,407 a \\
\hline CV $(\%)$ & 20,323 & 16,942 & 14,977 & 15,364 \\
\hline \multicolumn{5}{|c|}{ Intervalo de corte (semanas) } \\
\hline 8 & 79,2 & 30,51 & 7,294 & 4,691 \\
\hline 9 & 87,5 & 33,56 & 7,182 & 5,209 \\
\hline 10 & 95,8 & 32,28 & 9,765 & 7,282 \\
\hline 11 & 87,5 & 38,31 & 11,656 & 8,849 \\
\hline Equação $(Y=)$ & ns & $\begin{array}{l}-10,382+4,236 x \\
R^{2}=0,8678^{*}\end{array}$ & $\begin{array}{l}0,673+0,252 x \\
R^{2}=0,8854^{* *}\end{array}$ & $\begin{array}{l}0,028+0,274 x \\
R^{2}=0,9614^{* *}\end{array}$ \\
\hline
\end{tabular}

* Médias seguidas de mesma letra nas colunas não diferem entre si a $5 \%$ de probabilidade pelo teste de Tukey.

o corte a $10 \mathrm{~cm}$ proporcionou maior peso seco de caule (Tabela 3).

Por não haver diferenças significativas entre as duas alturas de cortes quanto ao peso seco de folhas, que são comercializadas, pode-se inferir que o diferencial de $5 \mathrm{~cm}$ de haste não contribui no aumento significativo, no entanto, implica em maior sobrevivência das plantas e no desenvolvimento mais rápido da rebrota. Isto pode ser explicado pela redução no estande, e conseqüente menor competição entre as plantas. $\mathrm{O}$ intervalo de corte influenciou significativamente as variáveis altura de planta e peso seco de folhas e caules/planta (Tabela 3). Nas três variáveis a regressão linear explica melhor os resultados e a colheita 11 semanas após o primeiro corte proporcionou os maiores valores (Tabela 3). Em alfavaca-cravo (Ocimum gratissimum L.), Cruz et al. (2001) observaram que o corte a $30 \mathrm{~cm}$ de altura, com o intervalo de 120 dias, proporcionou maior rendimento de biomassa.
Conclui-se neste ensaio que o corte a $5 \mathrm{~cm}$ de altura diminuiu a sobrevivência de plantas rebrotadas e não influenciou o peso seco de folhas/planta. A colheita da rebrota pode ser feita 11 sema-

\section{AGRADECIMENTOS}

Os autores agradecem ao ETENE/ FUNDECI/BNB pelo financiamento desta pesquisa e ao CNPq pela concessão da bolsa de produtividade do Prof. Arie F. Blank e DCR de Marcelo da C. Mendonça e Renata Silva-Mann.

\section{LITERATURA CITADA}

BACCHI, E.M. Controle de qualidade de fitoterápicos. In: DI STASI, L.C. (org.). Plantas medicinais: arte e ciência, um guia de estudo interdisciplinar. São Paulo: UNESP, 1996, p.169-185. BEZERRA, A.M.E.; MOMENTÉ, V.G.; ARAÚJO, E.C.; MEDEIROS FILHO, S. Germinação e desenvolvimento de plântulas de melão-de-sãocaetano em diferentes ambientes e substratos. $\mathrm{Ci}$ ência Agronômica, v.33, n.1, p.39-44, 2002. nas após o primeiro corte.
BLANK, A.F.; ARRIGONI-BLANK, M.F.; SILVA, P.A.; TORRES, M.E.R.; MENEZES, H.J.A. Efeitos de composições de substratos na produção de mudas de quiôiô (Ocimum gratissimum L.). Ciência Agronômica, v.34, n.1, p.105-108, 2003. CHAVES, F.C.M. Produção de biomassa, rendimento e composição de óleo essencial de alfavaca-cravo (Ocimum gratissimum $L$.) em função da adubação orgânica e épocas de corte. 2002. 144 f. (Tese Doutorado) - UNESP, Botucatu.

CRUZ, G.F.; INNECCO, R.; MATTOS, S.H. Determinação da altura e número de cortes da alfavacacravo. Horticultura Brasileira, Brasília, v.19, n.2, 2001. Suplemento CD-ROM. Trabalho apresentado no $41^{\circ}$ Congresso Brasileiro de Olericultura, 2001. HERTWIG, I.F. Plantas aromáticas e medicinais; plantio, colheita, secagem e comercialização. São Paulo: Icone, 1986. 449 p.

INNECCO, R.; CRUZ, G.F.; VIEIRA, A.V.; MATTOS, S.H.; CHAVES, F.C.M. Espaçamento, época e número de colheitas em hortelã-rasteira. Ciência Agronômica, v.34, n.2, p.247-251, 2003. MINAMI, K. Adubação em substrato. In: KÄMPF, A.N.; FERMINO, M.H. (eds.) Substrato para plantas: a base da produção vegetal em recipientes. Porto Alegre: Genesis, 2000. p.147-152.

MOL, D.J.S.; SILVA, F.G.; PINTO, J.E.B.P.; CARDOSO, M.G.; NASCIMENTO, V.E.; BERTOLUCCI, S.K.V. Acúmulo da biomassa e rendimento de óleo essencial de carqueja em função de sistemas de manejo e alturas de corte. Horticultura Brasileira, Brasília, v.20, n.2, 2002. Suplemento CD-ROM. Trabalho apresentado no $42^{\circ}$ Congresso Brasileiro de Olericultura, 2002. MOMENTÉ, V.G.; BEZERRA, A.M.E.; INNECCO, R.; MEDEIROS FILHO, S. Propagação vegetativa por estaquia de mentrasto em diferentes substratos. Ciência Agronômica, v.33, n.2, p.5-12, 2002.

SADRAEI, H.; GHANNADI, A.; MALEKSHAHI, K. Relaxant effect of essentia oil of Melissa officinalis and citral on rat ileum contractions. Fitoterapia, n.74, p.445-452, 2003. SETUBAL, J.W.; NETO, A.F.C. Efeito de substratos alternativos e tipos de bandejas na produção de mudas de pimentão. Horticultura Brasileira, Brasília, v.18, Supl., p.593-594, 2000.

SOUSA, A.C.; ALVIANO, D.S.; BLANK, A.F.; ALVES, P.B.; ALVIANO, C.S.; GATTASS, C.R. Antitumor and antioxidant activities of essential oil of M. officinalis L. Journal of Pharmacy and Pharmacology, v.56, n.5, p.677-681, 2004.

STURION, J. A. Métodos de produção e técnicas de manejo que influenciam o padrão de qualidade de mudas de essências florestais. Curitiba: EMBRAPA, 1981. 18 p. (Documentos, 03 ). 